\title{
A prospective evaluation of blunt trauma abdomen in rural setup
}

\author{
Shah $\mathbf{Y}^{1}$, Singh $\mathbf{A}^{2}$, Bansod P. $\mathbf{Y}^{3}$, Akhtar $\mathbf{M}^{4}$ \\ ${ }^{1}$ Dr. Yunus Shah, Associate Professor, ${ }^{2}$ Dr. Alok Singh, Junior Resident, ${ }^{3}$ Dr. Prasad Y. Bansod, Senior \\ Resident, ${ }^{4}$ Dr. Murtaza Akhtar, Prof \& HOD, all authors are affiliated with Department of Surgery, NKP Salve \\ Institute of Medical Sciences, Nagpur, Maharashtra, India.
}

Address for Correspondence: Dr. Prasad Y. Bansod, Email: rabbu7288@gmail.com

\begin{abstract}
Introduction: Blunt abdominal trauma accounts for the majority of abdominal injuries seen in the Emergency Department. It is responsible for substantial morbidity and mortality. Selecting appropriate approach has been recently a point of conflict in management of abdominal blunt trauma, and criteria for non- operative management are being changed frequently. Objective: With aim to identify some of the determining factors of successful non-operative management. Methods: A 2 year tertiary care teaching hospital based longitudinal study was done. Selection criteria were defined and a prestructured proforma was made to assess and note the findings. Results: 34 patients were studied. $29.4 \%$ of patients were in the age group of $>20-30$ years with the mean age $35.29 \pm 15.84$ years. $79.4 \%$ were male. Road traffic accident was responsible for $79.4 \%$ of blunt abdominal trauma cases while majority of the patients presented with abdominal pain (91.2\%) and abdominal tenderness $(91.2 \%)$. Associated extra abdominal injuries were found in 10 cases. The common extra abdominal injuries were head injuries (14.7\%). 9 patients underwent exploratory laparotomy. 25 were selected for nonoperative management. The most commonly injured organ was spleen (38.9\%) followed by liver \& stomach. 3 patients died in the present study. The sensitivity and specificity of the Emergency USG findings were $80.9 \%$ and $92.3 \%$ respectively, and that of the CT findings were $100 \%$ and $0 \%$ respectively. Conclusion: Non operative management (NOM) was found to be highly successful and safe. Hemodynamic stability along with ultra sound, CT scan and repeated clinical examination were the sheet anchors of NOM
\end{abstract}

Keywords: Blunt trauma abdomen, Polytrauma, Exploratory laparotomy, Ultrasonography, CT scan, Liver injury, Spleen injury

\section{Introduction}

Blunt abdominal trauma (BAT) accounts for the majority of abdominal injuries seen in the Emergency Department [1]. It is responsible for substantial morbidity and mortality. Around 75\% of BAT cases are related to motor vehicle collision (MVC) or vehicle versus pedestrian accidents [2]. Blows to the abdomen (15\%) and falls (6-9\%) are also responsible [3]. Occult BAT may occur with child abuse and domestic violence. It has been reported that about $31 \%$ of patients with multiple trauma suffer from abdominal injuries [4-5]. The spleen and liver are the most commonly injured solid organs in BAT [2-3]. About $13 \%$ and $16 \%$ of these patients have hepatic and splenic injuries

Manuscript received: $7^{\text {th }}$ April 2017

Reviewed: $17^{\text {th }}$ April 2017

Author Corrected: $26^{\text {th }}$ April 2017

Accepted for Publication: $4^{\text {th }}$ May 2017 respectively [6]. Injuries to the pancreas, bowel and mesentery, bladder, and diaphragm, as well as retroperitoneal structures (kidneys, abdominal aorta), are less common but must also be considered. According to standard ATLS guideline, all the patients with blunt abdominal injuries who are hemodynamically unstable and have signs of exsanguination should undergo emergency laparotomy, however, selecting these patients, especially in the multiple trauma patients remains a challenge [7]. High rate of operative complications caused paradigm shift from operative to nonoperative management in hemodynamically stable blunt abdominal trauma patients [8-9]. Repeated clinical examination supplemented with modern imaging and laboratory investigations play a key role in reaching therapeutic decisions, thus 
preventing unnecessary laparotomies [10]. Since the issue of selecting the most appropriate approach has been recently a point of conflict in management of internal bleeding following an abdominal blunt trauma, and criteria for non- operative management are being changed frequently, we are going to identify some of the determining factors of successful non-operative management, in our trauma centre. Hence the present study was done to evaluate the various modes of clinical presentation of patient with blunt trauma abdomen and its management, and to study the role of Emergency sonography, and to study the role of conservative and surgical management of blunt trauma abdomen.

\section{Materials and Methods}

The present study was carried out in a tertiary care hospital situated in a rural area from September 2014 to November 2016. We evaluated the patients of blunt trauma abdomen in view of modes of presentation, clinical features, study of emergency USG, CT Scan, various other imaging investigations and assess the outcome of conservative and surgical intervention. A total of minimum 34 cases were prospectively enrolled on the basis of inclusion and exclusion criteria.

Study design-The present study was a longitudinal study.

Study setting-The present study was a tertiary care hospital based study.

\section{Inclusion criteria}

- Patient admitted with the history of blunt trauma abdomen of all age group.

- Clinical findings like guarding, rigidity, distension of abdomen.

- Patient of polytrauma with above criteria present.

\section{Exclusion criteria}

- Patient not willing to be admitted or getting evaluated or left hospital

- Patients who expired before complete evaluation.

Study population- All cases of trauma with suspicion of abdominal trauma.

Ethical clearance- Study was granted by Institute Ethics Committee (IEC)
Assessment variables- Various demographic factors, history, clinical features, and symptoms like pain \& distention of abdomen, vomiting, urinary retention, \& haematuria. Basic laboratory investigations and radiological investigations were noted. Emphasis was laid upon Ultrasonography of abdomen and pelvis.

Ultrasonography was done in radiology room which was just adjacent to casualty. USG was done with the patient in the supine position to evaluate for the presence of free fluid. The pelvis was also scanned. Subxiphoid views of the heart were obtained when there was a history of possible chest trauma.

Computed tomography of abdomen and pelvis was advised only in hemodynamically stable patients of blunt abdominal trauma whenever indicated. CT scans were obtained by giving IV contrast material.

Patients were initially scanned from the xiphoid to the symphysis pubis. All images were interpreted immediately by the on-call radiologist.

Laparotomy was done, if indicated, after a written valid and informed consent. Initial resuscitation at casualty was as per the standard protocol of Basic life support (BLS) and Advanced Trauma Life Support (ATLS). Evaluation of patient was done to identify life threatening injuries at earliest for emergency surgery.

Implementation of Non-operative Management (NOM)- Those patients who were haemodynamically stable, showed absence of peritoneal irritation were selected for non-operative management. Following imaging, injury to viscus was ruled out.

\section{Management of Individual Organ Injuries}

Liver Injuries: Non operative approach: CT criteria showing no evidence of active bleeding / expanding hematoma for Grade I to III injury.

Exploratory laparotomy- in hemodynamically unstable, any grade biliary tract trauma.

Splenic Injury: Non-operative management was done if there was non-penetrating trauma or isolated splenic injury (grades 1-2) and in alert patient (no head injury or intoxication). 
Pancreas: Exploration was indicated if there was disruption of main pancreatic duct, to control haemorrhage, to control bacterial contamination, debride devitalized pancreatic tissue and to preserve at least $20-50 \%$ of functional pancreatic tissue. We also aimed to provide adequate internal or external drainage of pancreatic injuries.

Kidneys: For minor injuries: Type I, II, Contusion, Laceration, conservative management was planned whereas for major injuries: Type III, IV Rupture Shattered kidney, Pedicle injury, surgical management was planned.

Protocol: All patients were kept in the Intensive Care Unit (ICU) with strict bed rest. The routine management followed was nil orally, nasogastric tube aspiration, intravenous fluids blood transfusion as and when necessary, broad spectrum antibiotics, monitoring of vital signs, Abdominal girth etc.

Criteria \& Technique of operative managementPatients were taken up for operative intervention if they showed hemodynamic instability, peritoneal irritation, and e/o: hollow viscus injury, severe solid viscus injury or failure of non-operative management. A midline approach was used as a standard protocol in all cases. The findings at laparotomy were noted as amount of hemperitoneum or pus and faecal and biliary contamination, organ injured and the site and extent of injury, state of viscera and any other incidental findings. The procedure done varied as per the findings. The abdomen closure was done with nonabsorbable monofilament polyamide suture in all cases after peritoneal wash. Drain were placed accordingly. Post operatively, patients were managed on IV fluids, blood transfusions, broad spectrum antibiotics and analgesics.

Complications like postoperative septicaemia, wound infection, chest infection were recorded and dealt accordingly. Drains were removed postoperatively when they stopped draining. Suture removal was done appropriately. In patients who expired the cause of death was noted.

\section{Statistical methods}

Descriptive statistics- The data was presented as mean, standard deviation, range and others for descriptive statistics like Age, Gender \& Clinical presentation.

Analytical statistics- Qualitative data was represented in the form of percentages. Quantitative data was calculated using mean \pm SD and/or median with range. Sensitivity, specificity positive predictive value, negative predictive value and diagnostic accuracy of the methods were calculated. Results were represented graphically. MS Office 2013 and SPSS version 20 was used for most analysis.

\section{Results}

A hospital based longitudinal study was done and a total of 34 patients were assessed. Majority of the patients $(29.4 \%)$ were in the age group of $>20-30$ years. The age of the patients ranged from 17-69 years and the mean age was $35.29 \pm 15.84$ years (Table 1 ).

Table-1: Distribution of patients according to age.

\begin{tabular}{|c|c|c|}
\hline Age & $\mathbf{N}$ & $\mathbf{\%}$ \\
\hline$>10-20$ & 7 & $20.6 \%$ \\
\hline$>20-30$ & 10 & $29.4 \%$ \\
\hline$>30-40$ & 7 & $20.6 \%$ \\
\hline$>40-50$ & 5 & $14.7 \%$ \\
\hline$>50-60$ & 1 & $2.9 \%$ \\
\hline$>60-70$ & 4 & $11.8 \%$ \\
\hline Total & 34 & $100 \%$ \\
\hline Mean \pm SD & & $35.29 \pm 15.84$ \\
\hline
\end{tabular}

Majority of the patients were male (79.4\%) whereas female patients constituted $20.6 \%$ of the study group. The male to female ratio was 3.86:1. Road traffic accident (RTA) was responsible for $79.4 \%$ of blunt abdominal trauma cases, while fall from height and physical assault accounted for $14.7 \%$ and $5.9 \%$ of cases respectively. 
Majority of the patients presented with abdominal pain (91.2\%) and abdominal tenderness (91.2\%) followed by abdominal guarding (38.2\%) and abdominal guarding (33.3\%).

Table-2: Distribution of patients according to Clinical Presentation.

\begin{tabular}{|c|c|c|}
\hline Clinical Presentation & $\mathrm{N}$ & $\%$ \\
\hline Abdominal pain & 31 & $91.2 \%$ \\
\hline Abdominal tenderness & 31 & $91.2 \%$ \\
\hline Abdominal guarding & 13 & $38.2 \%$ \\
\hline Rebound tenderness & 11 & $33.3 \%$ \\
\hline Free fluid & 10 & $29.4 \%$ \\
\hline Absent bowel sounds & 9 & $26.5 \%$ \\
\hline Abdominal distension & 9 & $26.5 \%$ \\
\hline Rigidity & 9 & $26.5 \%$ \\
\hline Vomiting & 5 & $14.7 \%$ \\
\hline Haematuria & 2 & $6.7 \%$ \\
\hline
\end{tabular}

As per the distribution of patients according to interval between time of injury to presentation, $50 \%$ patients were present in the hospital in $>2-4$ hrs after injury while $23.5 \%$ and $20.6 \%$ of the patients were present in $>4-6$ and $>6$ hours respectively. $5.9 \%$ patients could be present in $\leq 2$ hours after injury. According to the distribution of patients according to associated trauma extra abdominal injuries were found in 10 cases. The common extra abdominal injuries were head injuries (14.7\%).

After a detailed clinical evaluation and suitable investigations, 9 patients underwent exploratory laparotomy. 25 patients were selected for non-operative management because they had no signs of peritonitis or they had hemperitoneum without hemodynamic instability. Ground glass appearance diaphragm was found in 6 cases while Gas under diaphragm was found in 4 cases. 27 patients had Emergency USG detected solid organ injuries for which they underwent laparotomy and found to have significant injuries. 7 patients had Emergency USG detected normal solid organs with free fluid and found to have hollow viscus injury at laparotomy. Splenic and renal laceration was common in 2 patients (Table 3 )

Table-3: Organ wise injuries of patients as assessed by FAST \& CT

\begin{tabular}{|c|c|c|c|}
\hline Organ wise Injury & $\begin{array}{c}\text { Number of patients } \\
\text { with injury }[\mathbf{N}(\%)]\end{array}$ & $\begin{array}{c}\text { CT scan Findings of } \\
\text { patients }[\mathbf{N}(\boldsymbol{\%})]\end{array}$ & $\begin{array}{c}\text { Emergency USG FAST } \\
\text { Findings of patients [N }(\%)]\end{array}$ \\
\hline Spleen & $14(38.9 \%)$ & $8(22.2)$ & $13(38.2 \%)$ \\
\hline Liver & $12(33.3 \%)$ & $10(27.8 \%)$ & $11(32.4 \%)$ \\
\hline Stomach & $4(11.1 \%)$ & Not assessed & Not assessed \\
\hline Renal & $3(8.3 \%)$ & $3(8.3 \%)$ & Not assessed \\
\hline Pancreas & $1(2.8 \%)$ & $1(2.8 \%)$ & Not assessed \\
\hline Duodenum & $1(2.8 \%)$ & Not assessed & $7(20.6 \%)$ \\
\hline Bladder & $1(2.8 \%)$ & $1(2.8 \%)$ & $7(20.6 \%)$ \\
\hline Free fluid without solid \\
organ injury
\end{tabular}

CT Scan Findings of patients- CT Abdomen was done in 22 patients and CT scan detected liver laceration in 10 patients and splenic laceration in 8 patients. 3 patients had kidney laceration while 1 patient each had injury to bladder wall and pancreatic laceration. Splenic and renal laceration was common in 2 patients. (Table 4) The most commonly injured organ was spleen $(38.9 \%)$ followed by liver $(33.3 \%)$, stomach $(11.1 \%)$, renal $(8.3 \%)$, pancreas $(2.8 \%)$, duodenum $(2.8 \%)$ and bladder $(2.8 \%)$. Splenic and renal laceration was common in 2 patients (Table 3). 
Operative Procedures Done- Out of 12 patients with liver laceration, 3 patients underwent surgery in which Laceration Repair \& Gelatine sponge kept. Out of 14 patients with splenic injury, 1 patient underwent splenectomy while rest was managed conservatively. Primary closure with omental patch was done in 4 patients while distal pancreatectomy \& drain was kept in 1 patient. (Table 4)

Table-4: Operative Procedures Done

\begin{tabular}{|c|c|c|}
\hline Operative Procedures Done & $\mathbf{N}$ & $\%$ \\
\hline Primary closure with omental patch & 4 & $11.8 \%$ \\
\hline Liver laceration Repair \& Gelatine Sponge Kept & 3 & $8.8 \%$ \\
\hline Splenectomy & 1 & $2.9 \%$ \\
\hline Distal pancreatectomy \& drain kept & 1 & $2.9 \%$ \\
\hline
\end{tabular}

The common post-operative complications were surgical site infection (5.8\%) followed by ARDS (2.9\%) and resuturing (2.9\%). (Table 5)

Table-5: Post-operative Complications

\begin{tabular}{|c|c|c|}
\hline Post-operative Complications & N & \% \\
\hline Surgical site infection & 2 & $5.8 \%$ \\
\hline Acute respiratory distress syndrome (ARDS) & 1 & $2.9 \%$ \\
\hline Resuturing & 1 & $2.9 \%$ \\
\hline
\end{tabular}

Duration of Hospital Stay: The range varied from 8-45 days. The mean duration of stay in hospital was 15 days. (Table 6)

3 patients died in the present study. One died due to hypovolemic shock after being brought to casualty ward while the remaining two patients with multiple liver laceration and pancreatic laceration died due to septicaemia.

Table-6: Duration of Hospital Stay.

\begin{tabular}{|c|c|c|}
\hline Duration of Hospital Stay (days) & $\mathbf{N}$ & $\mathbf{\%}$ \\
\hline $\mathbf{< 1 0}$ & 9 & $26.7 \%$ \\
\hline $\boldsymbol{> 1 0 - 2 0}$ & 17 & $50 \%$ \\
\hline$>\mathbf{2 0 - 3 0}$ & 5 & $13.2 \%$ \\
\hline $\mathbf{> 3 0 - 4 0}$ & 2 & $6.6 \%$ \\
\hline$>\mathbf{4 0}$ & 1 & $3.3 \%$ \\
\hline
\end{tabular}

Table-7: Correlation between Emergency USG and CT Findings.

\begin{tabular}{|c|c|c|c|}
\hline & & Intra-abdominal & Intra-abdominal \\
\hline & & injury +ve & injury -ve \\
\hline Emergency & Positive & 17 & 1 \\
\hline \multirow[t]{2}{*}{ USG $(n=34)$} & Negative & 4 & 12 \\
\hline & Present & 22 & 0 \\
\hline CT $(n=22)$ & Absent & 0 & 0 \\
\hline
\end{tabular}

Table 8: Correlation between Emergency USG and CT Findings

\begin{tabular}{|c|c|c|c|c|c|}
\hline & Sensitivity & Specificity & PPV & NPV & ACCURACY \\
\hline Emergency & $\mathbf{( \% )}$ & $(\boldsymbol{\%})$ & $\mathbf{( \% )}$ & $(\%)$ & $(\%)$ \\
\hline USG & $80.9 \%$ & $92.30 \%$ & $94.4 \%$ & $75 \%$ & $85.2 \%$ \\
\hline CT & $100 \%$ & $0 \%$ & $100 \%$ & $0 \%$ & $100 \%$ \\
\hline
\end{tabular}


Emergency USG was done on all 34 patients. CT scan was done in 22 patients, out of which 17 solid organ injuries was correctly detected by USG. There were 4 false negative reports of no solid organ injury and 1 report of false positive for solid organ injury in Emergency USG findings. The sensitivity and specificity of the Emergency USG findings were $80.9 \%$ and $92.3 \%$ respectively, with the accuracy of $85.2 \%$. The sensitivity and specificity of the CT findings were $100 \%$ and $0 \%$ respectively, with the accuracy of $100 \%$. (Table $7 \& 8$ )

\section{Discussion}

A hospital based study was done with 34 patients to assess blunt trauma abdomen. Blunt abdominal trauma is a hazardous task even to the best of traumatologists. Abdominal findings may be absent in $40 \%$ of patients with hemperitoneum. Sometimes clinical evaluation of blunt abdominal injuries may be masked by other more obvious external injuries [11].

Trauma is one of the most common causes of death in the young population (age group between 1 and 45 years). Blunt abdominal trauma (BAT) is very common, and the prevalence of intra-abdominal injury following it has been reported to be as high as $12-15 \%$. The mechanisms resulting in BAT were motor vehicle collision $(73 \%)$, motorcycle collision (7\%), auto-pedestrian collision $(6 \%)$, and fall $(6 \%)$ [12].

The abdomen is the third most common injured region, in $25 \%$ of cases who require surgical interference. Abdominal trauma is classified as either blunt or penetrating. Penetrating abdominal trauma is easily diagnosed, while blunt trauma complications can be missed if the clinical signs are not evident. [13] Haemodynamic instability, disturbed level of consciousness and presence of other injuries in the skull, chest, pelvic bones or extremities, all explain the need of an accurate and rapid imaging tool to diagnose associated abdominal visceral injuries [14].

Contrast enhanced computed tomography (CT) is the radiological golden standard for abdominal visceral injuries. However, renal failure or a previous anaphylactic reaction to contrast material hinders the use of CT in evaluation of some trauma patients. A non-contrast study diminishes the sensitivity of CT in diagnosis of solid organ injuries [15]. CT disadvantages include the need for patient transfer to the CT unit, hazards of ionizing radiation or if contrast media is used, patients may not be co-operative or assume the best position if in pain or with disturbed conscious level. Thus, nonelevated arms, or medical devices (catheters, tubes and lines) will cause artefacts decreasing imaging quality [16]. Organ injury can be easily diagnosed by abdominal ultrasound as well as the presence of free intra-abdominal fluid, which could be blood or intestinal secretions that provides indirect evidence of these injuries.

Ultrasound is non-invasive, portable using no ionizing radiation, repeatable, and easily performed in the emergency unit, at the same time with resuscitation methods. Focused abdominal sonography for trauma (FAST) is a fast examination method that could demonstrate intraperitoneal fluid. Several studies found this technique to be sensitive (79-100\%) and specific (95.6-100\%), particularly in hemodynamically unstable patients [17].

In the present study, majority of the patients (29.4\%) were in the age group of $>20-30$ years followed by $20.6 \%$ in the age groups of $>10-20$ years and $>30-40$ years. The age of the patients ranged from 17-69 years and the mean age was $35.29 \pm 15.84$ years.

The commonest age group affected was 21-30 years $(52 \%)$. According to previous studies conducted by Baker SP et al [18] and Guirguis IEM et al [19] commonest age group affected was 21-30 years, the incidence being $29.4 \%$ and $20.6 \%$ respectively. This can be attributed to heavy vehicular traffic, overcrowded trains, inter gang rivalry where young adults are mainly involved.

A marked male preponderance was observed in our study. $79.4 \%$ of the patients were male and remaining $20.6 \%$ were female patients. Male: female ratio was 3.89:1. Rhodes $M$ et al [20] reported a male: female ratio of 2.4:1. Similarly Enderson BL et al [21] reported a ratio of $3.2: 1$.This can be attributed to facts that in our country, even today majority of the outdoor task are carried out by males. In a similar study done by Ravi Kanth J et al [22] 61(93.8\%) were males and $4(6.2 \%)$ females. 
Road traffic accident (RTA) was responsible for $79.4 \%$ of blunt abdominal trauma cases, while fall from height and physical assault accounted for $14.7 \%$ and $5.9 \%$ of cases respectively. Rhodes $M$ et al [20] and Kreis DJ et al [23] also reported vehicular accidents as commonest mode of injury with incidence being $70 \%$ and $80 \%$ respectively. Majority of the patients presented with abdominal pain $(91.2 \%)$ and abdominal tenderness $(91.2 \%)$.

The time lapse between injury to admission affects outcome. In our study no patient were presented in first golden hour. Majority of the patients $(50 \%)$ were present in the hospital in $>2-4$ hrs after injury while $23.5 \%$ and $20.6 \%$ of the patients were present in $>4-6$ and $>6$ hours respectively. $5.9 \%$ patients could be present in $\leq 2$ hours after injury. It is crucial to get the medical aid to trauma patients as early as possible so as to resuscitate the patient before he/she succumbs to the injuries. Baron Laireg, Napoleon Chief Surgeon, developed the concept of air ambulance to reduce the time required to provide definitive care to the injured (Orsekovitch 1986) [24]. But in our country the concept of field resuscitation by paramedical squad is still in an infant stage and air ambulance services are not well developed. It is extremely difficult to implement due to two reasons; a) Financial constraints b) non-availability of space.

In our study, associated extra abdominal injuries were found in 10 cases. The common extra abdominal injuries were head injuries (14.7\%). In our study $29.3 \%$ patients had associated injuries which included head injury, chest injury and long bone fractures. In previous studies Allen RB et al [25] and Cox EF et al [26] reported associated injuries in $61 \%$ and $50.3 \%$ of cases respectively. Associated injuries increase morbidity and mortality in blunt abdominal trauma cases. In our series out of three patients, who died, two had associated injuries. A similar study done by Boutros SM et al [27], out of the 15 patients with intra-abdominal injury, 5 patients had liver injury, 6 patients had splenic injury, 3 patients had renal injury and one patient had intestinal injury. In a similar study done by Ravi Kanth J et al [22], the authors observed that the patients who had sustained blunt abdominal trauma may have sustained injury simultaneously to other systems and it is particularly important to examine for injuries of head, thorax and extremities.
After a detailed clinical evaluation and suitable investigations, 9 patients underwent exploratory laparotomy. 25 patients were selected for nonoperative management because they had no signs of peritonitis or they had hemperitoneum without hemodynamic instability. In a similar study done by RaviKanth $\mathrm{J}$ et al $81 \%$ (53 patients) of cases underwent successful conservative treatment with a failure rate of $7.5 \%$ (4 patients) and 19\% (12 patients) operative treatment.

Ground glass appearance diaphragm was found in 6 cases while Gas under diaphragm was found in 4 cases. Emergency USG detected solid organ injuries in 27 patients. On Emergency USG 7 patients were detected to have normal solid organs with free fluid and out of which 4 patients were found to have hollow viscus injury during laparotomy. Splenic and renal laceration was common in 2 patients.

In a study done by Boutros SM et al, 3 cases of renal injury were reported, one of them had large renal hematoma, marked intra-abdominal bleeding and hemodynamic instability that urgent exploration and left total nephrectomy were done, the other 2 cases were hemodynamically stable, one of them had sub capsular hematoma while the other had perinephric hematoma and renal laceration; however, ultrasonography could not detect the exact extension of the injury and could not exclude injury of collecting system, CECT was performed, and the case of sub capsular hematoma was treated conservatively while the other case needed surgical treatment. In a study done by Sato M et al [28], they reported that ultrasonography was found to detect and classify parenchymal injuries efficiently, when done by experienced examiners despite disadvantages in detecting superficial and vascular injuries.

CT Abdomen was done in 22 patients and CT scan detected liver laceration in 10 patients and splenic laceration in 8 patients. 3 patients had kidney laceration while 1 patient each had injury to bladder wall and pancreatic laceration. Splenic and renal laceration was common in 2 patients. Boutros SMet al observed that Patients with small splenic or hepatic injuries who were hemodynamically stable do not need further investigations and are treated conservatively. Patients with major splenic or hepatic injuries and who are hemodynamically 
stable could perform CT abdomen for accurate characterization of their injuries. In cases of renal trauma, the exact extent of injury should be assessed for accurate therapy choice. Tears that expand into or through the pelvi-calyceal system (grade IV and higher) and ureteric injuries are not very obvious on sonography if there is no significant urinary leakage. Jalli $R$ et al [29] suggested that CT scan is the modality of choice in hemodynamically stable patients who have major suspicions for renal injuries. Korner $M$ et al [30] observed Delayed contrast-enhanced CT performed 10 min after contrast injection can easily show extravasation from the pelvi-calyceal system or the ureters and, thus, delineate the location and extent of damage.

The most commonly injured organ was spleen $(38.9 \%)$ followed by liver $(33.3 \%)$, stomach $(11.1 \%)$, renal $(8.3 \%)$, pancreas $(2.8 \%)$, duodenum $(2.8 \%)$ and bladder $(2.8 \%)$. Splenic and renal laceration was common in 2 patients. This compares favourably with similar studies carried out by Cox EF et al, who reported splenic injury $(42.2 \%)$ followed by liver $(35.6 \%)$ and intestine and mesentery injury (17\%). In Gerald WS et al [31] also reported spleen as commonest injured organ $(26 \%)$ followed by intestine and mesentery $(21 \%)$ and liver (19\%) in their study. Boutros SMet al in a study showed that $40 \%$ of cases with intraabdominal injury had splenic injury, 33\% had hepatic injury, $20 \%$ had renal injury and $7 \%$ had intestinal injury.

Intra-peritoneal bleeding is mainly caused by liver and spleen rupture and if not managed properly can lead to hypovolemia and subsequent death [7]. There are two general approaches for treatment of intra- peritoneal bleeding followed by blunt abdominal trauma; surgical and non-surgical approaches. Recent guidelines on management of hepatic injuries indicate that non-operative management of blunt hepatic injuries currently is the treatment modality of choice in hemodynamically stable patients, irrespective of the grade of injury or patient age [11].

Non-operative management of blunt hepatic injuries should only be considered in an environment that provides capabilities for monitoring, serial clinical evaluations, and an operating room available for urgent laparotomy.
Patients presenting with hemodynamic instability and peritonitis still warrant emergent operative intervention [11]. The similar guideline has been published in regards to blunt splenic injuries [3234]. Out of 12 patients with liver laceration, 3 patients underwent surgery in which liver laceration repair was done and gelatine sponge was kept. Out of 14 patients with splenic injury, 1 patient underwent splenectomy while rest was managed conservatively.

Primary closure with omental patch was done in 4 patients while distal pancreatectomy \& drain was kept in 1 patient. In the study of RaviKanth $\mathrm{J}$ et al [23] procedures done for splenic trauma were splenectomy in 3 patients. Bowel repair and resection was done in 5 patients. Nephrectomy was done in 3 patients. Laparotomy and bladder repair was done in 2 patients. IVC repair was done in 1 patient.

In a similar study done by Carlin AM [35] splenectomy was done in higher grade of splenic trauma i.e. grade IV, V. One patient of liver laceration, who was subjected to surgery, required perihepatic packing. The remaining cases of liver trauma were managed conservatively, successfully. Out of four patients of traumatic small bowel injury, in two patients' primary closure of perforation was carried out and remaining two resection anastomosis was carried out. Scott LS et al [36] gave the principles of treatment of traumatic small bowel injury, which included freshening of edges, restoration bowel continuity and liberal irrigation of peritoneal cavity. All three cases of pancreatic injuries were managed conservatively out which one with pancreatic duct tear with peripancreatic collection required pig tailing of the collection, followed by ERCP and stenting of pancreatic duct was carried out.

The common post-operative complications were surgical site infection (5.8\%) followed by ARDS $(2.9 \%)$ and resuturing $(2.9 \%)$. In a study done by Majid Set al [37] commonest postoperative complication was ARDS 7(11\%) managed conservatively and early diagnosis decreased mortality by $50 \%$.

The mean duration of stay in hospital is 15 days in our study. The range varied from 8-45 days. 3 patients died in the present study. One died due to 
hypovolemic shock after being brought to casualty ward while the remaining two patients with multiple liver laceration and pancreatic laceration died due to septicaemia whereas in a similar study done by RaviKanth J et al [23] mortality was seen in $13(20 \%)$ cases. Commonest cause was polytrauma in 11 followed by sepsis/ARF in 2 patients. Post-operative complications most frequently observed were ARDS-7(11\%), sepsis$6(9 \%)$, renal failure-4(6\%), wound infection-4 (6\%), DVT-1, hemobilia-1 traumatic pancreatitis-1.

The haemodynamically stable patient is defined as a patient with a systolic blood pressure $(\mathrm{SBP})>90$ $\mathrm{mmHg}$, heart rate $>120 \mathrm{bpm}$ and without clinical signs of shock. Emergency USG was done on all 34 patients. CT scan was done in 22 patients, out of which 17 solid organ injuries was correctly detected by USG.

There were 4 false negative reports of no solid organ injury and 1 report of false positive for solid organ injury in Emergency USG findings. The sensitivity and specificity of the Emergency USG findings were $80.9 \%$ and $92.3 \%$ respectively, with the accuracy of $85.2 \%$. The sensitivity and specificity of the CT findings were $100 \%$ and $0 \%$ respectively, with the accuracy of $100 \%$.

In a study done by Mohammadi A et al [38] there was one case of intestinal injury, ultrasonography just detected the intra-peritoneal free fluid, injury could not be seen and CT abdomen with contrast was done and detected intestinal injury. In patients with negative initial FAST but sustained abdominal symptoms, repeated sonography after 12 to $24 \mathrm{~h}$ can facilitate a diagnosis of gastrointestinal tract injury. Lee BC et al [39] reported that bowel and mesenteric injuries are not associated with a significant amount of abdominal free fluid in hypotensive patients and may cause false-negative results on FAST; clinical follow up and CT scanning should be considered to prevent this probability.

Finally in this study non operative management (NOM) for BTA was found to be successful and safe in majority of the patients.

\section{Conclusion}

Non operative management (NOM) for BTA was found to be highly successful and safe.
Hemodynamic stability along with ultra sound, CT scan and repeated clinical examination were the sheet anchors of NOM. Definitive indications for laparotomy were hemodynamic instability and peritonitis. Patients with initial Hemodynamic instability, haemorrhagic shock are associated with a high risk for NOM failure. USG in haemodynamically unstable patients, CECT in stable patients were investigations of choice. Associated injuries influenced morbidity and mortality.

\section{Funding: Nil, Conflict of interest: None Permission of IRB: Yes}

\section{References}

1. Nishijima DK, Simel DL, Wisner DH, Holmes JF. Does this adult patient have a blunt intraabdominal injury?. JAMA. 2012 Apr 11;307(14): 1517-27.

2. Isenhour JL, Marx J. Advances in abdominal trauma. Emergency medicine clinics of North America. 2007 Aug 31;25(3):713-33.

3. Davis JJ, Cohn Jr IS, Nance FC. Diagnosis and management of blunt abdominal trauma. Annals of surgery. 1976 Jun;183(6):672.

4. Shah SM, Shah KS, Joshi PK, Somani RB, Gohil VB, Dakhda SM. To study the incidence of organ damage and post-operative care in patients of blunt abdominal trauma with haemoperitoneum managed by laparoscopy. Journal of minimal access surgery. $2011 \mathrm{Jul} ; 7(3): 169$.

5. Deunk J, Brink M, Dekker HM, Kool DR, Blickman JG, van Vugt AB, Edwards MJ. Predictors for the selection of patients for abdominal CT after blunt trauma: a proposal for a diagnostic algorithm. Annals of surgery. 2010 Mar 1; 251 (3):512-20.

6. Abbasi HR, Mousavi SM, Akerdi AT, Niakan $\mathrm{MH}$, Bolandparvaz S, Paydar S. Pattern of traumatic injuries and Injury Severity Score in a major trauma center in Shiraz, Southern Iran. Bulletin of emergency \& trauma. 2013 Apr;1(2):81

7. Gwinnutt CL, Driscoll PA. Advanced trauma life support. European journal of anaesthesiology. 1996 Feb 1;13(02):95-101. 
8. Giannopoulos GA, Katsoulis IE, Tzanakis NE, Patsaouras PA, Digalakis MK. Non-operative management of blunt abdominal trauma. Is it safe and feasible in a district general hospital?. Scandinavian journal of trauma, resuscitation and emergency medicine. 2009 May 13;17(1):22.

9. Hashemzadeh SH, Hashemzadeh KH, Dehdilani $\mathrm{M}$, Rezaei S. Non-operative management of blunt trauma in abdominal solid organ injuries: a prospective study to evaluate the success rate and predictive factors of failure. Minerva chirurgica. 2010 Jun;65(3):267-74.

10. Raza M, Abbas Y, Devi V, Prasad KV, Rizk KN, Nair PP. Non operative management of abdominal trauma-a 10 years review. World Journal of Emergency Surgery. 2013 Apr 5;8(1):14.

11. Hassan R, Aziz AA. Computed tomography (CT) imaging of injuries from blunt abdominal trauma: a pictorial essay. The Malaysian journal of medical sciences: MJMS. 2010 Apr;17(2):29.

12. Kendall J, Kestler AM, Whitaker KT, Adkisson MM, Haukoos JS. Blunt abdominal trauma patients are at very low risk for intra-abdominal injury after emergency department observation. Western Journal of Emergency Medicine. 2011 Jan 1;12(4).

13. Baradaran H, Salimi J, Nassaji-Zavareh M, Rabbani AK. Epidemiological study of patients with penetrating abdominal trauma in Tehran-Iran. Acta Medica Iranica. 2007;45(4):305-8.

14. Farrath S, Parreira JG, Perlingeiro JA, Solda SC, Assef JC. Predictors of abdominal injuries in blunt trauma. Revista do Colégio Brasileiro de Cirurgiões. 2012 Aug;39(4):295-301.

15. Hedrick TL, Sawyer RG, Young JS. MRI for the diagnosis of blunt abdominal trauma: a case report. Emergency radiology. 2005 Jul 1;11(5): 309-11.

16. Cokkinos D, Antypa E, Stefanidis K, Tserotas P, Kostaras V, Parlamenti A, Tavernaraki K, Piperopoulos PN. Contrast-enhanced ultrasound for imaging blunt abdominal trauma-indications, description of the technique and imaging review. Ultraschall in der Medizin-European Journal of Ultrasound. 2012 Feb;33(01):60-7.
17. Kontopodis N, Kaouraki A, Panagiotakis GI, Miliadis O, Volakakis J, Spiridakis K. Diagnosis of intra-abdominal injuries can be challenging in multitrauma patients with associated injuries. Our experience and review of the literature. Il giornale di chirurgia. 2013;33(1/2):27-31.

18. Baker SP, O'neill B. The injury severity score: an update. Journal of Trauma and Acute Care Surgery. 1976 Nov 1;16(11):882-5.

19. Guirguis EM, Hong C, Liu D, Watters JM, Baillie F, McIntyre RW. Trauma outcome analysis of two Canadian centres using the TRISS method. Journal of Trauma and Acute Care Surgery. 1990 Apr 1;30(4):426-9.

20. Rhodes M, Aronson J, Moerkirk G, Petrash E. Quality of life after the trauma center. Journal of Trauma and Acute Care Surgery. 1988 Jul 1;28 (7):931-8.

21.Enderson BL, Reath DB, Meadors J, Dallas W, Deboo JM, Maull KI. The tertiary trauma survey: a prospective study of missed injury. Journal of Trauma and Acute Care Surgery. 1990 Jun 1;30 (6):666-70.

22. Ravikanth J, Gejji SB, H KRC. Our Experience in Blunt Trauma Abdomen. Int J Sci Res. 2015;4(8):75-7. http://www.ijsr.net/archive/v4i8/ SUB157202.pdf

23. Kreis Jr DJ, Fine EG, Gomez GA, Eckes J, Whitwell E, Byers PM. A prospective evaluation of field categorization of trauma patients. Journal of Trauma and Acute Care Surgery. 1988 Jul 1;28 (7): 995-1000.

24. Oreskovich MR, Carrico CJ. Pancreaticoduodenectomy for trauma: a viable option?. The American journal of surgery. 1984 May 1;147(5):618-23.

25. Allen RB, Curry GJ. Abdominal trauma: a study of 297 consecutive cases. The American Journal of Surgery. 1957 Mar 1;93(3):398-404.

26. Cox EF. Blunt abdominal trauma. A 5-year analysis of 870 patients requiring celiotomy. Annals of surgery. 1984 Apr; 199 (4): 467. 
27. Boutros SM, Nassef MA, Abdel-Ghany AF. Blunt abdominal trauma: The role of focused abdominal sonography in assessment of organ injury and reducing the need for CT. Alexandria Journal of Medicine. 2016 Mar 31; 52 (1): $35-41$.

28. Sato M, Yoshii H. Reevaluation of Ultrasonography for Solid-Organ Injury in Blunt Abdominal Trauma. Journal of ultrasound in medicine. 2004 Dec 1;23(12):1583-96.

29. Jalli R, Kamalzadeh N, Lotfi M, Farahangiz S, Salehipour M. Accuracy of sonography in detection of renal injuries caused by blunt abdominal trauma: a prospective study. Ulus Travma Acil Cerrahi Derg. 2009 Jan 1;15(1):23-7.

30. Körner M, Krotz MM, Degenhart C, Pfeifer KJ, Reiser MF, Linsenmaier U. Current Role of Emergency US in Patients with Major Trauma 1. Radiographics. 2008 Jan;28(1):225-42.

31. Shaftan GW. Indications for operation in abdominal trauma. The American Journal of Surgery. 1960 May 1;99(5):657-64.

32. Raza M, Abbas Y, Devi V, Prasad KV, Rizk KN, Nair PP. Non operative management of abdominal trauma-a 10 years review. World Journal of Emergency Surgery. 2013 Apr 5;8(1):14.

33. Stassen NA, Bhullar I, Cheng JD, Crandall M, Friese R, Guillamondegui O, Jawa R, Maung A, Rohs Jr TJ, Sangosanya A, Schuster K. Nonoperative management of blunt hepatic injury: an Eastern Association for the Surgery of Trauma practice management guideline. Journal of Trauma and Acute Care Surgery.2012 Nov1;73(5):S288-93.
34. Stassen NA, Bhullar I, Cheng JD, Crandall ML, Friese RS, Guillamondegui OD, Jawa RS, Maung AA, Rohs Jr TJ, Sangosanya A, Schuster KM. Selective nonoperative management of blunt splenic injury: an Eastern Association for the Surgery of Trauma practice management guideline. Journal of Trauma and Acute Care Surgery. 2012 Nov 1; 73(5):S294-300.

35. Carlin AM, Tyburski JG, Wilson RF, Steffes C. Factors affecting the outcome of patients with splenic trauma/Discussion. The american surgeon. 2002 Mar 1;68(3):232.

36. Stevens SL, Maull KI. Small bowel injuries. Surgical Clinics of North America. 1990 Jun 30;70 (3): 541-60.

37. Shojaee M, Dolatabadi AA, Sabzghabaei A, Malekirastekenari A, Faridaalaee G, Yousefifard M, Yaseri M. New scoring system for intraabdominal injury diagnosis after blunt trauma. Chinese journal of traumatology. 2014 Feb 1;17 (1): $19-24$

38. Mohammadi A, Ghasemi-rad M. Evaluation of gastrointestinal injury in blunt abdominal trauma" FAST is not reliable": the role of repeated ultrasonography. World Journal of Emergency Surgery. 2012 Jan 20;7(1):2.

39. Lee BC, Ormsby EL, McGahan JP, Melendres GM, Richards JR. The utility of sonography for the triage of blunt abdominal trauma patients to exploratory laparotomy. American journal of roentgenology. $2007 \quad$ Feb; $188 \quad$ (2): 415-21.

\section{How to cite this article?}

Shah Y, Singh A, Bansod P.Y, Akhtar M. A prospective evaluation of blunt trauma abdomen in rural setup. Int J Med Res Rev 2017;5(07):691-701. doi:10.17511/ijmrr. 2017.i07.07. 